\title{
Digital organization: Transformation into the new reality
}

\author{
Vladimir I. Ananyin \\ Senior Lecturer, Department on Business Processes Management \\ The Russian Presidential Academy of National Economy and Public Administration \\ Address: 82, Prospect Vernadskogo, Moscow, 119571, Russian Federation \\ E-mail:v.ananiin@gmail.com
}

\section{Konstantin V. Zimin}

Editor-in-Chief, Information Management Journal

Member of the Board, The Russian Union of CIO

Address: 34, Seleznevskaya Street, Moscow, 123056, Russian Federation

E-mail: konst.zimin@gmail.com

\section{Mikhail I. Lugachev}

Professor, Head of Department of Economic Informatics

Lomonosov Moscow State University;

Academic Supervisor, IBS Corporate University

Address: 1, build. 46, GSP-1, Leninskie Gory, Moscow, 119991, Russian Federation

E-mail:mlugachev@gmail.com

\section{Rinat D. Gimranov}

Head of IT Department, OJSC Surgutneftegaz;

Head of Surgutneftegaz Department of Vocational Relationships

Surgut State University

Address: 1, block 1, Grigoriya Kukuevitskogo Street, Surgut, 628415, Russian Federation

E-mail:gimranov_rd@mail.ru

\section{Kirill G. Skripkin}

Associate Professor, Department of Economic Informatics

Lomonosov Moscow State University;

Address: 1, build. 46, GSP-1, Leninskie Gory, Moscow, 119991, Russian Federation

E-mail: k.skripkin@gmail.com

\begin{abstract}
This article discusses the characteristic changes in management practices occurring in the context of the digital transformation of business. It shows the mutual interconnections of these changes, as well as the links to changes in the organizational culture of the organization. Among the new management practices reviewed are those both at the level of the enterprise as a whole (digital products, digital business models, digital management of value creation chains, digital business processes), as well as on the local level in adoption of management decisions - unlimited knowledge and management of the enterprise in real time (Real Time Enterprise). The article demonstrates the need for formation of certain cultural norms in the organization, including total knowledge management and an orientation to rapid changes. Review is made of the succession and qualitative distinctions of traditional automation from digitalization of enterprises. We discuss the possibility of using theories and methods connected with such concepts as complementary assets for research into new forms of organization for the digital enterprise.
\end{abstract}

The article also presents a research program conducted in the framework of a program for digital transformation of activities of the OJSC Surgutneftegaz, Orbita 2.0. In the given research program the accent is placed on analysis of the problem of sustainability of the organization. In order for the 
organization to be flexible and changeable, it should periodically be in a condition of instability. In the contrary case, strong resistance to change will develop in it. The search for principles and forms of organization ensuring the controllability of sustainable organizations is an important area of this research.

Key words: digital organization, complementary assets, real time enterprise, volatility, sustainability, controllability of an organization.

Citation: Ananyin V.I., Zimin K.V., Lugachev M.I, Gimranov R.D., Skriprin K.G.(2018) Digital organization: Transformation into the new reality. Business Informatics, no. 2 (44), pp. 45-54.

DOI: $10.17323 / 1998-0663.2018 .2 .45 .54$

\section{Introduction}

$\mathrm{T}$ The practice of building digital organizations on the basis of new Information Technologies is taking its first steps. This practice has been given the name "Digitalization." The enthusiasm of the professional community will be fed by great expectations and first practical results. The first practical steps towards realization of digital business show that digitalization really can provide important competitive advantages. One can say that the "race for technological rearmament" is already proceeding at full speed. The leaders of this race are demonstrating clearly that you cannot enjoy the competitive advantages of using the new technologies without profound transformation of your business, including its organizational and human capital. When it became comprehensible that the transformation affects not only the business but also economic and social institutions, states also entered the "race for technological rearmament." Most states of developed and developing countries already have national programs for developing their digital economies, and Russia is no exception.

Many technologies are undergoing realization in the form of commercial products, but all participants of this race already understand that the technologies will continue to develop at a fast pace while the market for new prod- ucts is only just being born. In these conditions, many leaders are seeking to "try out" these new technologies, namely:

$\checkmark$ to gain experience using the technologies;

$\downarrow$ to understand the competitive advantages they can give to their business;

$\checkmark$ to determine the directions and scale of the transformation of their business;

$\downarrow$ to evaluate their business risks related to this transformation.

The methods and instruments of management used by the business also must be transformed. Every method has not only its intended purpose but also conditions for its application. In the new conditions, old methods can turn out to be inappropriate and become unnecessary or even dangerous for the business. Digital transformation also requires modernization of the ideas of the professional community about management, as well as the search for new ones and the modernization of existing methods and instruments of management.

\section{Development of systems for managing organization and complementary assets}

Global and also some domestic leaders of digitalization are demonstrating very clearly that it often leads to profound transformation of the entire business. Such a transformation 
can radically change the logic of the business itself and, as a consequence, change the structure of its material and intangible assets. Therefore, analysis of digitalization of the organization requires an approach which, when solving all tasks, allows us to constantly keep in mind an integral concept of this organization. One can say that such an approach must see the business as a whole when looking at each element of the business.

As in economics, so in scientific management there is a widespread idea of the importance of complementary interconnections both between organizational practices of the enterprise and between these practices, IT and the requirements for human capital. P. Milgrom and J. Roberts [1] speak about complementary connections between the elements of a company's strategy. M. Porter $[2,3]$ speaks about interconnected forms of activity as the basis of strategy, and H. Mintzberg [4] - about the interconnected elements of organizational design. Given all the distinctions in terminology, we are talking about the same phenomena - complementary interconnections between practices and characteristics distributed among three groups of assets: human, organizational and computer capital [5].

Human capital includes the visible and unseen knowledge of employees, their ability to learn, the shared language of communication, culture, shared values and mutual trust.

Organizational capital includes approaches and principles for organizing activity, the practices of decision-making, the distribution and transfer of responsibility, the business processes and rules, standards and methods, technological processes, as well as the information used in the activity. These assets can relate to various levels: to the level of working groups, subdivisions, to a group of subdivisions within the organization, to the organization as a whole or to interaction of the organization with external contractors.
Computer capital includes Information Systems - the sources of data, systems for processing, transfer and storage of data, the practices and processes of working with these systems, as well as data which give rise to Information Systems.

The connection between the enumerated complementary assets appears when we consider that in real organizations they, like puzzles, mutually supplement each other, forming an individual profile of the organization. In organizations there are always all three groups of complementary assets and if the organization is in a stable condition, then these assets are complementary to each other. However, this is just a static picture. In motion, everything is somewhat more complex.

In fact, in the complementary assets there is a certain degree of volatility (or, on the contrary, sustainability). Among various assets, it is not identical. One or several complementary assets turn out to be (for various reasons) more movable and variable than others. As a result, this asset (or group of assets), while changing somewhat faster than others, plays the role of locomotive of change: its change along the chain of complementary connections provokes change in other complementary assets. Thus, in the trends of organizations there are more volatile assets and other assets which remain behind and slow them down (via complementary interconnections). As the static condition is approached, there forms a new network of complementary interconnections which will correspond to the changed assets, as a result of which there arises a new profile of complementary assets of the organization.

On the other hand, in the profile of complementary assets we see reflected not only the diversity of organizations but also common tendencies of their development. History shows that in the course of a rather extended period of time the various practices from one of the three groups of complementary assets is more volatile. The change trends of these assets deter- 
mine not only the development of the organization but also (to a significant degree) their competitive advantages. From this point of view, the history of the development of enterprises can be divided into three periods.

1. Human capital assets are the most volatile. Before the appearance of manufacturing production, the efficiency of activity and competitive advantages of a business were determined not so much by technologies and by the organization as by the personal mastery of those doing the work, as well as by the informal relations within the organization. All the necessary information about the work was transferred in words and was stored in paper documents. Precisely the trends of human capital determined the development trends of the organization. In this period, human capital was the most volatile group of complementary assets.

2. Organizational capital assets are the most volatile. Beginning at the end of the $18^{\text {th }}$ century (the emergency of manufacturing production), we see the change-over of the more mobile group of complementary assets from human to organizational capital. The appearance of serial and mass production required new forms of organization. The strong trends of organized capital led to the spread of the mass conveyor and large serial production in the first half of the 20th century. The development trends of the computer capital were not high, although there appeared arithmometers and office technologies for workflow oriented towards paper document management.

3. Computer capital assets are the most volatile. The widespread use at the end of the 20th century of digital computers for automation of separate operations and business functions of organizations became the starting point of active growth of another group of complementary assets - computer capital. The explo- sive growth of information which organizations encountered is the consequence of the strong trends of computer capital. This growth quickly led to the automation of business processes of organizations and then to the emergence of digital products.

Today the trends in change of computer capital are not declining and this has led to a transition "to digits" of business models of enterprises and even of value creation chains in which they enter. This gives grounds for viewing the digital organization as an organization in which the most volatile group of assets is computer capital.

Thus, we can understand digitalization of the organization to mean a transformation whereby the role of locomotive of change is played by complementary assets of computer capital. We will speak of the digital organization as an organization in which the most volatile complementary asset is the assets of computer capital.

We note that apart from volatility there is another characteristic of complementary assets. From the research of H. Mintzberg [4] we see that not all complementary assets are equally important for the organization. Coordination of the activity in the organization can be done by various mechanisms. The leading role of one or another mechanism of coordination, according to Mintzberg, leads to certain sustainable forms (configurations) of organizations. This mechanism of coordination apparently must rely on one or several complementary assets. A sustainable profile of complementary assets nonetheless must be fully formed, but one or several complementary assets in it must play such a role as the nucleus plays in the atom ${ }^{1}$. For example, in the organizations which Mintzberg called mechanical structures, the "nuclear" assets are the rules and business processes (part of the organizational capital).

\footnotetext{
${ }^{1}$ We note that the nucleus cannot in any way be considered the most important element of the atom; the picture is rather more complicated. Therefore, the

"nuclear" complementary asset should not be considered the main or dominant one. Its role is to support the mechanism of coordination
} 
On the other hand, in simple structures [4] the "nuclear" complementary asset is the loyalty of the personnel and of external contractors (part of the human capital).

In the general case, "nuclear" complementary assets and the most volatile complementary assets are not one and the same assets. And their correlation in this or another case is the subject of further research. However, one may suppose that the sustainability of the organization is sensitive in the maximum degree precisely to the resilience of the "core" complementary asset. Therefore, analysis of the complementary assets of the organization (showing the composition of the practices and characteristics, their connections and the dominant) is an important instrument for diagnosis, for forecasting the sustainability and planning for changes. In the works of K.G. Skripkin [6] there is a description of an approach to analysis of the complementary assets at the level of practices and characteristics of the organization. The method of complementary assets through uncovering the connections between the various practices of the organization provides good pointers for research into the mechanisms of influence of new Information Technologies on possible competitive advantages and the business risks of the organization.

Preservation of the tendency of greatest volatility of computer capital inevitably leads to restructuring the complementary connections between assets, and of the most complementary assets. This is the very transformation of the business which the digitalization of enterprises launches. And here the main questions arise for research into the digital organization:

$\diamond$ What can the appearance of the digital organization be both at the level of the generalized profile of complementary assets and at the level of concrete practices and characteristics of the organizational, human and computer capital?

$\diamond$ Under what conditions will the profile of the digital organization be sustainable?
By what stages can one move forward to the creation of this profile?

$\diamond$ Which competitive advantages can a digital organization obtain and what are its risks at each stage?

\section{New practices of the digital organization}

Digital organizations are not so much new technologies as they are a new organization of the business in principle. Digitalization has led to the emergence of new and to the transformation of old management practices. If we generalize a multitude of research and the practices of building elements of the digital organizations, we can highlight several of their characteristic signs $[7,8]$.

The signs of the organization as a whole (viewing the organization from outside) reflect the management practices of organizational capital:

$\downarrow$ Digital products. In the entire content of the product, the material and physical shifts away to digital. The material-physical form of the product does not disappear; but the use of the product becomes impossible without its digital presentation. Such a presentation of a real object has been given the name "digital twin." For example, in machine-building the basic value starts to be represented not by the material-physical product nor by the documentation relating to it (even if it is electronic), but the electronic (digital) model of the article according to which the article can be produced, serviced and restored. The electronic model of the article is surrounded by a multitude of services which also become digital products;

^ Digital business models. The possibility to use the 'digital twin' of a delivered complex piece of equipment in combination with uninterrupted monitoring of all its elements and processes has led to the emergence of radically new business models. For example, companies which produce complex equipment are shift- 
ing from the supplier business model to the service model when what is being sold is not the equipment and its technical support but the guaranty of its uninterrupted work or readiness for use (for example, flight hours or volumes of pumped air). Digital business models require not only a profound digitalization of all the internal links of the enterprise's value creation (design, production, logistics, technical support and maintenance of products), but also the building of close partnership relationships between the business and all its contractors. The most important element of such a profound partnership is the creation of an overall integrated information and communications space. The integration of the information space can be accomplished, for example, on the basis of the "digital twin" of the article and plans for coordination of the movement of orders along the value creation chain. Then a multitude of routine daily interactions of the participants of the chain can be changed into the form of digital services offered by outside organizations (analytics, advice, applications, proposals, competitions, call centers);

^ Digital value chain management. The business of a digital organization is specialized and integrates into a profound cooperative network with all its contractors and clients. In this network, the organization integrates into the market value chains. In this case, it is necessary to have management of the business not only at the level of the organization itself but also at the level of the entire market value chain. We can give as an example the value chain in machinebuilding: the management company - the general contractor - the experimental design bureau - the producers of components - the main serial production - the clients - the centers of after-sales service. Each organization is independent, but at the same time enters into a multitude of chains and therefore must coordinate not only its own operational activity but also its interaction with all participants of each chain. Recently many global companies have begun to create business platforms. A business platform is the company's business model on which the contractors of this company can quickly create their own value chains, attracting ever more new participants, while the company itself obtains a mechanism for managing these chains;

$\downarrow$ Digital business processes. The processes for operating the digital product themselves become digital. This is especially clear in the example of documents which have become digital. In this case, the users can work with a digital document only with the help of special applications, and the logic of coordination of actions of these users also requires special applications and data.

Signs in the field of managing separate elements of the organization (view of the organization from inside - at the level of decision-making) reflect the practices of computer capital. Digitalization creates a new information space of the business and opens it up widely for the organization's employees. Such an information space goes well beyond the boundaries of the digital organization itself and spreads along all the value creation chains of contractors. Thanks to powerful smart means of processing and analysis of data, employees receive practically unlimited knowledge to solve their tasks. Data become not simply big data; a multitude of connections appear in them that were not visible before. In a number of instances, the information space begins to show features of a hologram, when in a separate fragment of the space a user can restore many other of its fragments.

Among the new practices of human capital are the following:

$\diamond$ Without knowledge, you cannot extract information from the data, and they thus remain incomprehensible. Without knowledge, you cannot find data in the information space, and even set the task for such a search and analysis. The quickly growing complexity of the information space requires similarly quick growth in the scale and complexity of 
employees' knowledge. Therefore the arrangement for management of corporate knowledge is critically important for the digital organization. Without this, all its participants "will be speaking in different languages."

Unlimited knowledge is not necessary and even is dangerous for an implementer, who does not want to see anything further away than his current functional obligations. The digital organization cannot exist without culture oriented towards changes in which quick changes and leadership are the most important cultural values. It is precisely such employees who need to make decisions; they are the ones who need unlimited information;

$\diamond$ Management of the organization in real time regime (the Real Time Enterprise, RTE [9]). Digitalization gives us the possibility to receive information without delay in something close to "real time." In combination with quick assembly of knowledge which dominates the culture oriented towards changes and with flexible forms of organization, this, in turn, makes it possible to save time and raise the quality of decision-making at all levels of managing the business. Quick decision-making and higher quality levels of decisions make it possible to implement these decisions more quickly, i.e., to carry out changes. Growing knowledge in combination with a culture oriented towards change and new forms of organization open up for employees new possibilities and also risks to their business; they stimulate the organization further for change (all the more so if the product is digital since changes in the "ciphers" can be carried out an order of magnitude faster than "in metal"). Initial experience with digitalization shows that in such organizations there is rapid growth of the level of volatility not only in the organizations themselves but also in the value creation chains into which these organizations enter;

$\diamond$ Human labor is forced out of regular routine activity and is replaced by work using inbuilt intelligence that is capable of learning. In regular routine activity, a living person is the bottleneck and in conditions of digitalization he or she is significantly supplanted by artificial intelligence. Such replacement extends not only to those who work with physical valuables (for example, qualified workers, operators, drivers) but also those who work with intangibles (for example, bookkeepers, lawyers, secretaries). What remains are functions which robots cannot perform (possibly for the time being): making complex management decisions, strategic, crisis management, business development. The work places of the remaining personnel risk being "devoured" by artificial intelligence robots.

\section{How traditional automation differs from digitalization}

Digital organizations are not appearing in a vacuum. They have been preceded by a long history of automation. Here the question immediately arises: how in principle does automation of a company's organization differ from digitalization? Do some radically new qualities arise in the organization from using new Information Technologies or is this simply a quantitative change? After all, during automation of business processes data (entities) describing real objects were used in Information Systems. Why can't they be called perhaps simple but nonetheless "digital twins" of real objects? Why can't you call business models "digital" if Information Systems are used to manage the inter-relationships with clients and/or suppliers (CRM/SRM) together with systems of through-going planning of enterprise resources (ERP)? After all, doesn't automation require serious re-preparation of personnel and development of its motivation? After all, doesn't automation require changes to business processes and to the organizational structure?

Whereas automation created in the organization an information space which only partially reflected the space of physical reality, digitalization sets things up so that the information space must become the "digital twin" of physical real- 
ity. The reflection of reality and picture of the world which we find in Information Systems begin to become close to reality. Today only a few organizations can boast that the data in their Information Systems draws as rich a picture of the world, with intense nuances, as does our direct perception of the situation. The automation of the last fifty years essentially did not set for itself such a task. In digital organizations, this gap must be closed, all of which leads to qualitative changes in management and in organizational capital.

Digitalization gradually "draws into" (makes virtual) its information space not only the physical reality in which a person lives but also the person himself. This is not only the creation of artificial intelligence robots, but also the digital "prosthesis of his organs of feeling and intellectual capabilities. One can say that digitalization "has also infringed on" the human capital of the organization, all of which, apparently, must lead to qualitative changes not only in the management culture but also in human culture generally.

Thus, in the digital organization computer capital becomes the driver of changes, as a consequence of which all the remaining complementary assets begin to undergo change. At the same time, there must be essential changes in the practices of the organizational and human capital. It seems that we have entered the time when the accumulation of quantitative changes in the field of speed and volume of data processing, miniaturization of devices and their mobility, the quantity of participants in the information space and their activity lead to qualitatively new forms of organization for enterprises, markets and the whole economy.

The directors of many companies have understood very well that digitalization is not a fashion or an epidemic from which you can hide and for which you can wait until it passes. Like previous technological revolutions which led to the formation of a new reality, digitalization is creating a new reality before our eyes. The signs of a digi- tal organization introduced above are the pronounced symptoms of the new reality. Of course, each director can find his own path in this new reality, but the problem is that it has begun to change, one may say, before our eyes, and now just the general contours have become obvious. But these contours are still quite insufficient for a leader to be able to work out an articulate strategy for his business. He needs to "feel his way" by trial and error. Here the real practice of digital transformation has moved well ahead of scientific understanding of these changes of reality in the field of economic, management and social sciences. These sciences still have to rehabilitate themselves before the directors-practitioners by rendering the help they are capable of in the search for pathways to digital transformation of their business.

IT-oriented enterprises and enterprises providing services have come closest to digital transformation from the beginning. It seemed to them simplest of all to get along with the digital twin of physical reality. Nonetheless, capital-intensive businesses with a large amount of material assets such as, for example, Russian oil companies also have moved towards digital transformation.

\section{The program of digital transformation of the activity of OJSC Surgutneftegaz, Orbita 2.0}

A certain initial level of digitalization (informatization) already has been achieved by the oil companies, including OJSC Surgutneftegaz. The oil fields are equipped with various sensors and controllers. The management of the working regimes of the pumps in the wells is performed adaptively and remotely. All production facilities have the necessary means of measurement and monitoring. The Information Systems (analytical, accounting and management) process and store a significant volume of data, while all the basic SAP systems have been redeployed on the "in-memory" SAP HANA platform. A protected electronic 
workflow is being developed. Part of the major construction works are being designed in the form of digital models (Building Information Models, BIM). An ancillary trend is ensuring independence from imports: many of the Information Systems developed in-house are moved onto a Database Management System (DBMS) with open code or domestic, geoinformation systems which have already been fully redeployed on domestic applied software and free software programs DBMS.

Taking into account the new technological achievements and the current level of development, at present an important task is to determine both the target status of digitalization of the oil company and the priority for implementation of various technologies and realization of stages to the achievement of the target condition. At the same time, an understanding of the potentially revolutionary nature of the changes forces us to think about questions of sustainability of the organizational structure, processes of management and development strategy.

A program of multi-faceted improvement of the controllability and efficiency of business processes at OJSC Surgutneftegaz, Orbita 2.0 is being developed in order to:

$\checkmark$ validate the operability of the technologies and gain experience in using them;

$\downarrow$ understand which competitive advantages they can give to the business;

- select the most appropriate technologies and determine the special features of their application in a concrete enterprise;

$\downarrow$ determine the direction and scale of transformation of the business and changes in the Information Systems and infrastructure;

$\downarrow$ evaluate the business risks and technological risks linked with this transformation.

Many business processes traditionally were designed for conditions of considerable delays in transfer and processing of information. One of the most outstanding examples is setting up procedures for calculating costs and closing the accounting period. A cardinal acceleration of these processes (from days down to hours) lays down a powerful base for further changes, but also introduces potential risks, because managers at all levels gain access to information practically in real time, while the management system presupposes a certain cyclical nature of receiving and processing information and taking management decisions.

Within the framework of the Orbita 2.0 program, research is being carried out also into the sustainability of business processes that have undergone digitalization. It is believed that the capability of carrying out fast change should emerge in such business practices. At the same time, the capability of fast change should be accompanied by a reduced level of sustainability of the business process itself, i.e., the business process should have a reduced resistance to changes. Here there arises a scientific research task - to find those principles and forms of organization which will ensure the controllability of non-resilient business processes.

Scientific research into sustainability is being carried out in the following areas:

- search for factors and criteria of sustainability of business processes;

- evaluation of the real time scale of business processes up to and after their digitalization;

- search for principles and forms of organization ensuring the controllability of business processes both in conditions of their sustainability and when that is lost.

As a methodological basis of the given research, we use the methods developed in the following fields:

$\diamond$ complementary assets $[5,6]$;

$\diamond$ knowledge management [10, 11];

$\diamond$ theory of non-sustainable systems [12].

The research must result in the following final practical results:

$\diamond$ functioning and controlled digital business processes; 
$\checkmark$ a methodology for evaluating the sustainability of business processes;

$\checkmark$ recommendations on building forms of the organization which ensure the controllability of the business processes.

\section{Conclusion}

The "race of technological rearmament" based on digitalization has already begun and is quickly accelerating. Its main content is not so much the implementation of new Information Technologies as the digital transformation of the business. The changes to the business can be so fast and frequent that the traditional division of concepts of the functioning of the business and its change simply lose their sense. The transformations of business in connection with implementation of Information Technologies also occurred in the past. Previously in conditions of automation (informatization) transformation meant the shift of the business from one stable condition to another stable condition. As for the digital transformation, it launches an uninterrupted process of changes to the business in which its stability and sustainability will be ever more blurred, and the enterprises will become more and more changeable. The digital transformation affects not only the organization but also all societal institutions, including science. In this connection, management, as the science of running things must also go down the road of digital transformation. The concepts, methods and instruments of management must be brought into correspondence with the new realities. The testing of such correspondence must be carried out in real projects of digital transformation in real organizations.

In this article, we took the example of a program for multi-faceted improvement of controllability and efficiency of the OJSC Surgutneftegaz, Orbita 2.0. We formulated the areas of research into sustainability and ensuring the controllability of digital business processes, as well as the expected practical results of the research.

\section{Refereences}

1. Milgrom P., Roberts J. (1990) Economics of modern manufacturing: Technology, strategy, and organization. The American Economic Review, vol. 80, no. 3, pp. 511-528.

2. Porter M.E. (1996) What is strategy? Harvard Business Review, vol. 74, no. 6, pp. 61-78.

3. Porter M.E. (1998) On competition. Boston: Harvard Business School Press.

4. Mintzberg H. (1983) Structure in fives: Designing effective organizations. Englewood Cliffs, NJ: Prentice-Hall.

5. Lugachev M.I., Skripkin K.G., Ananiin V.I., Zimin K.V. (2013) Effektivnost' investitsiy v IT. Al'manakh luchshikh rabot [Efficiency of investments in IT. Almanac of the best papers]. Moscow: SoDIT (in Russian).

6. Skripkin K.G. (2017) Vliyanie vneshney sredy na organizatsionnyy dizayn obrazovatel'nogo uchrezhdeniya: instrumenty analiza [How environment influences on organizational design of educational institution: analytical instruments]. Modern Information Technologies and IT Education, vol. 12 , no. 3, pp. 225-236 (in Russian).

7. PwC (2017) «Industry 4.0»: Digital enterprise creation. Global analysis of concepts «Industry 4.0», 2016.

8. Agamirzyan I., Belousov D., Kuznetsov E., Zotov A., Danilin I., Holkin D., Shteinmuller A., Shteinmuller K., Proydakov A., Lukin E., Raevsky I., Lukyanenko S., Pervushin A. (2016) Vyzov 2035 [Challenge 2035]. Moscow: Olimp Business (in Russian).

9. Drobik A., Raskino M., Flint D., Austin T., MacDonald N., McGee K. (2002) The Gartner definition of Real-Time Enterprise. Gartner Research Note, 1 October 2002.

10. Snowden D. (2002) Complex acts of knowing: Paradox and descriptive self-awareness. Journal of Knowledge Management, vol. 6, no. 2, pp. 100-111.

11. Kurtz C.F., Snowden D.J. (2003) The new dynamics of strategy: Sense-making in a complex and complicated world. IBM Systems Journal, vol. 42, no. 3, pp. 462-483.

12. Nikolis G., Prigozhin I. (2007) Poznanie slozhnogo [Knowledge of complexity].Moscow, URSS (in Russian). 